\title{
Parvovirus ile Enfekte Köpeklerde Nötrofil/Lenfosit, Monosit/Lenfosit ve Platelet/Lenfosit Oranlarının Belirlenmesi ${ }^{\text {*] }}$
}

\author{
Didem PEKMEZCI* Zeynep Nurselin COLAK \\ Ondokuz Mayıs Üniversitesi, Veteriner Fakültesi, İ̧̧ Hastalıkları Anabilim Dalı, 55200, Kurupelit, SAMSUN, TÜRKIYYE
}

Atıf yapmak için: Pekmezci, D. \& Çolak, Z.N. (2021). Parvovirus ile Enfekte Köpeklerde Nötrofil/Lenfosit, Monosit/Lenfosit ve Platelet/Lenfosit Oranlarının Belirlenmesi. Anadolu Çev. ve Hay. Dergisi, 6(4), 585-591.

How to cite: Pekmezci, D. \& Çolak, Z.N. (2021). Determination of Neutrophil/Lymphocyte, Monocyte/Lymphocyte and Platelet/Lymphocyte Ratios in Dogs with Occurring Parvovirus Infection. J. Anatolian Env. and Anim. Sciences, 6(4), 585-591.

(iD): https://orcid.org/0000-0003-2072-8165 (iD): https://orcid.org/0000-0002-0631-5471
*Corresponding author's: Didem PEKMEZCí

Ondokuz Mayıs Üniversitesi, Veterine Fakültesi, İç Hastalıkları Anabilim Dalı, 55200, Kurupelit, SAMSUN, TÜRKIYE

凶: dkazanci@omu.edu.tr
Öz: Nötrofil/lenfosit oranı (NEU/LYM), monosit/lenfosit oranı (MONO/LYM), ve platelet/lenfosit oranı (PLT/LYM) inflamasyonun ucuz, tekrar kullanılabilen biyobelirteçlerini oluşturmaktadır. Bu çalışma ilk defa parvovirus enfeksiyonu (PVE) şekillenmiş köpeklerde NEU/LYM, MONO/LYM ve PLT/LYM değerlerini ortaya koymaktadır. Çalışmanın amacını ise tedavi öncesi PVE ile pozitif köpeklerin NEU/LYM, MONO/LYM ve PLT/LYM değerlerinin, sağlıklı kontrollere göre karşılaştırılması oluşturmuştur. On sekiz sahipli, 2-6 aylık, PVE pozitif köpek, çalışma grubunu oluşturmuştur. Yedi sahipli, 8-10 aylık yaş aralığında sağlıklı köpek ise kontrol grubunu oluşturmuştur. Gruplar arasında tedavi öncesi NEU/LYM, MONO/LYM karşılaştırılmasında PVE pozitif grubu NEU $(\mathrm{P}<0,001)$, LYM $(\mathrm{P}<0,05)$ değerleri kontrol grubuna göre istatistiksel olarak düşük bulunmuştur. Bununla birlikte, $P V E$ pozitif grubunda tedavi öncesi PLT/LYM seviyeleri kontrol grubuna göre istatistiksel olarak yüksek $(\mathrm{P}<0,001)$ tespit edilmiştir. PVE pozitif ve kontrol gruplarında PLT/LYM düzeyleri ise sırasıyla 1120,94 ve 135,26 olarak bulunmuștur. Sonuç olarak, bu ön çalıșma PLT/LYM oranın, PVE ile doğal olarak enfekte köpeklerde kolay, uygun maliyetli, objektif ve invazif olmayan yeni bir prognostik belirteç adayı olabileceğini göstermektedir. NEU/LYM, MONO/LYM, PLT/LYM ile ilgili çalışmaların kısıtlı varlığına rağmen, özellikle veteriner hekimlikte enfeksiyöz hastalıklarda daha ileri çalışmalara ihtiyaç duyulmaktadır.

Anahtar kelimeler: Köpek, monosit/lenfosit oran1, nötrofil/lenfosit oran1, parvovirus, platelet/lenfosit oran1.

\section{Determination of Neutrophil/Lymphocyte, Monocyte/Lymphocyte and Platelet/Lymphocyte Ratios in Dogs with Occurring Parvovirus Infection}

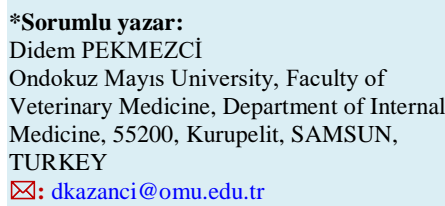

\begin{abstract}
Neutrophil/lymphocyte ratio (NEU/LYM), monocyte/lymphocyte ratio (MONO/LYM), and platelet/lymphocyte ratio (PLT/LYM) are inexpensive and reproducible biomarkers of inflammation. This is the first study that explores NEU/LYM, MONO/LYM, and PLT/LYM in dogs with Parvovirus infection (PVI). This study aims to determine whether the pretreatment NEU/LYM, MONO/LYM, and PLT/LYM differs in dogs with PVI against healthy controls. Eighteen client-owned dogs aged 2-6 months that were found positive with PVI were enrolled as the study group. Seven client-owned, healthy dogs of the 8-10 months formed the control group. Pretreatment NEU/LYM, MONO/LYM, and PLT/LYM were compared between groups. The pretreatment NEU $(\mathrm{P}<0.001)$ and LYM $(\mathrm{P}<0.05)$ levels were found to be significantly lower in the study group when compared to the control group. However, pretreatment PLT/LYM levels in the PVI positive group was significantly higher $(\mathrm{P}<0.001)$ than in the control group. PLT/LYM levels in the PVI and control groups were found as 1120.94 and 135.26, respectively. In summary, this preliminary study demonstrates that pretreatment PLT/LYM in dogs with PVI is an easy, cost-effective, objective, and non-invasive biomarker that
\end{abstract}


could be the new prognostic marker candidates in dogs naturally infected with PVI. Although limited studies on NEU/LYM, MONO/LYM, PLT/LYM are existed, especially further studies in veterinary medicine with infectious diseases are needed.

Keywords: Dog, monocyte/lymphocyte ratio, neutrophil/lymphocyte ratio, parvovirus, platelet/lymphocyte ratio.

\section{GIiRIŞ}

Kanin parvovirus tip 2 (CPV-2) dünya genelinde bulunan Parvoviridae ailesine ait (Decaro \& Buonavoglia, 2012) ve köpeklerin en önemli viral patojenleri arasında yer alan bir virüstür. CPV-2 küçük, zarfsız ve tek zincirli bir DNA yapısına sahip, CPV-2a, CPV-2b ve CPV-2c olmak üzere toplamda 3 varyanta sahip olabilen (Decaro \& Buonavoglia, 2012), hızla bölünen lenfoid doku hücrelerinde, bağırsak kript epitel hücrelerinde, kemik iliğindeki öncü hücrelerde ve bir aylıktan küçük köpek yavrularında miyokardiyositlerinde çoğalma yapısında bulanan bir virüstür (Goddard \& Leisewitz, 2010). CPV-2, genç hayvanlarda yüksek ölüm oranlarına sahip akut enteritise neden olurken yetişkinleri de etkilemektedir (Decaro vd., 2009). Klinik semptomları arasında anoreksiya, depresyon, kusma, aşırı hemorajik diyare, abdominal palpasyonda ağrı, dehidratasyon ve ateş yer alırken, daha şiddetli hematolojik değişiklikler kemik iliğinde hematopoietik progenitör hücrelerin yıkımının bir sonucu olarak görülmektedir ve en önemli bulgu hastada görülen lökopenidir (Mylonakis vd., 2016). Klinik belirtileri olan köpeklerden alınan dışkıların laboratuvar testlerine dayanarak gerçekleştirilerek yapılan son çalışmalarda çeşitli ülkeler arasında CPV-2 enfeksiyonu prevelansinın Hollanda'da \%23,6 (Decaro vd., 2011), İspanya'da \%27,7 (Duijvestijn vd., 2016), İtalya'da \%53,8, Fransa'da \%61,5, Almanya'da \%71,4, Kolombiya'da \%70,2 (Duque-García vd., 2017), Nijerya'da \%75 (Apaa vd., 2016), Çin'in bölgelerinde \%99,24 (Zhao vd., 2016), Bulgaristan'da \%91,67 (Filipov vd., 2016) ve Arnavutluk'ta \%92,98 (Cavalli vd., 2014), olduğu bildirilmiştir. Ülkemizde ise son yıllarda Dik ve Şimşek (2021) yılında 100 adet ishalli köpeğin dışkısının Polimeraz Zincir Reaksiyonu (PZR) ile \%66 oranında pozitiflik olduğunu tespit ederken, Gargari (2015) yılında gastroenteritis semptomu gösteren 100 adet köpeğin çeşitli marazi madde sıvilarının PZR ile incelemesinde 52 adet köpeğin pozitif (\%52) olduğunu tespit etmiştir. CPV-2, fekal-oral yol (doğrudan bulaşma) veya dışkı ile kontamine olmuş fomitlere oro-nazal maruziyet (dolaylı bulaşma) yoluyla köpekler arasında hızla yayılmaktadır (Smith-Carr vd., 1997). Virüsün fekal atılımının deneysel inokülasyondan 3 gün sonra olduğu gösterilmiştir ve virüs saçılımı klinik veya subklinik hastalıktan sonra maksimum 3 ila 4 hafta devam edebilmektedir (Macartney vd., 1984). Virüs replikasyonu oro-farenks, mezenterik lenf düğümleri ve timusun lenfoid dokusunda başlar ve hematojen yayılımla (enfeksiyondan 3-4 gün sonra) ince bağırsağın bağırsak kriptlerine yayılır (Hoskins, 1997; Smith-Carr vd., 1997). Enfeksiyondan 1 ila 5 gün sonra belirgin plazma viremisi gözlenir. Viremiden sonra, orofarenks, mezenterik lenf düğümleri ve timusun lenfoid dokusunda CPV-2 virüs replikasyonu başlar. Hematojen yayılımla (enfeksiyondan 3-4 gün sonra) ince bağırsağın bağırsak kriptlerine yayılır. Enfeksiyondan 1 ila 5 gün sonra ise belirgin plazma viremisi gözlenir. Viremiden sonra, CPV2 ağırlıklı olarak dili, ağız boşluğunu ve yemek borusunu kaplayan epitelde yerleşerek; ince bağırsak, kemik iliği, timus ve lenf düğümleri gibi lenfoid dokularda bulunur (Hoskins, 1997). Parvo Virus Enfeksiyonu (PVE) sonucu CPV köpeklerde akciğer, dalak, karaciğer, böbrek ve miyokarttan izole edilmiş olup, enfeksiyonunun sistemik bir hastalık olduğu da aslında ortaya birçok çalışma ile konmuştur (Hoskins, 1997; Smith-Carr vd., 1997). Prognostik testlerin mevcudiyeti, uygulayıcıyı klinik kararlar vermekten tamamen uzaklaştıramaz ve prognozun değerlendirilmesi PVE için halen zorlu bir konu olmaya devam etmektedir (Schoeman vd., 2013). Klinisyen, ölçülecek uygun testin hangisi olduğuna ve hangi sınır değerinin, PVE'li bir köpekte ötenazi veya tedaviye devam etme kararını desteklemek için yeterli kanıt oluşturacağına dair karar verme aşamasındaki stresli durumla çoğu zaman yüzleşmek zorundadır (Schoeman vd., 2013). Her ne kadar Mohr vd. (2003) PVE için ortaya koymuş oldukları klinik skor halen geçerliliğini koruyor olsa da; hayatta kalma, hastaneden taburcu olma süreçlerinin ve prognozun belirlenmesinde kullanılmak üzere yeni, uygun maliyetli laboratuvar biyo-belirteçlerinin oluşturulmasının faydalı olacağına dair görüşler güncelliğini korumaktadır (Prittie, 2004).

Hem beşerî hem de veteriner hekimlikte yapılan en yaygın laboratuvar testlerinden biri olan tam kan sayımı (CBC), farklı hücre türleri (örn. nötrofiller, lenfositler ve trombositler) arasındaki ilişkileri kolayca ve hızlı bir şekilde hesaplama imkânı sunmaktadır (Rejec vd., 2017). Nötrofiller, dolaşımdaki ilk fagositik hücrelerdir ve doğuştan gelen bağışıklığın çok önemli unsurlarıdır. İnflamatuar durumlarda, inflamatuar mediyatörler, zararlı patojenlerin fagosite edilerek kana göçlerini uyarırlar (Summers vd., 2010). 
NEU/LYM, MONO/LYM ve PLT/LYM basit laboratuvar koşullarında belirlenebilen, beyaz kan hücre sayılarından kolayca hesaplanan, düşük maliyetli ve tekrar üretilebilir testlerdir. Son zamanlarda beşerî hekimlikte araştırmacılar bu oranların, kardiyovasküler hastalıklar (Li vd., 2017), maligniteler (Min vd., 2017; Shi vd., 2017), akut pankreatitis (Wang vd., 2017), otoimmün hastalıklar (Chandrashekara vd., 2017) ve kronik obstrüktif akciğer hastalığı (Yao vd., 2017) gibi kronik tıbbi durumları olan hastalarda kötü prognoz veya majör inflamasyonun belirteçleri olarak kullanılabileceklerini ortaya koymuşlardır.

Bununla birlikte veteriner hekimlikte NEU/LYM, MONO/LYM ve PLT/LYM ile ilgili sınırlı çalışmalar bulunmakla beraber konu ile ilgili çalışmalara ilginin giderek arttığı görülmektedir (Burton vd., 2013; Rejec vd., 2017; Troìa vd., 2017; Hodgson vd., 2018; Çakır \& Pekmezci, 2019; Benvenuti vd., 2020; Gori vd., 2021; Neumann, 2021).

Sunulan çalışmanın amacını ise, beşerî hekimlikte birçok kronik ve akut inflamatuar hastalığın prognozunun belirlenmesinde düşük maliyeti sebebi ile kullanım sahası bulan NEU/LYM, MONO/LYM ve PLT/LYM değerlerinin PVE tanısı almış köpeklerdeki değerlerinin sağlıklı bireyler ile karşılaştırılarak veteriner hekimlikte bir kullanım alanına öncülük edip edemeyeceğinin araştırtılması oluşturmaktadır.

\section{MATERIAL AND METHOD}

Çalışma Materyali: Ondokuz Mayıs Üniversitesi Veteriner Fakültesi Eğitim Uygulama ve Araştırma Hastanesine 2019-2020 tarih aralı̆ğında ve hastane kayıt sisteminden getirilmiş sahipli, 2-6 aylık, aşısız, çeşitli cinsiyet ve ırktaki 18 adet dışkı örneklerinden CPV antijen yönünden hızlı test tanı kiti ile pozitif tanı alan köpekler ile aynı tarihlerde hastanemiz Doğum ve Jinekoloji Kliniği’ne elektif cerrahi için getirilmiş 7 adet klinik olarak sağlıklı 810 aylık, farklı irklarda, dişi köpeğin tam hemogram değerlerinin kayıtlarını oluşturmuştur. Çalışma hasta kayıtları üzerinden retrospektif olarak gerçekleştirilmiş olmakla birlikte, hasta sahiplerinin bilgilendirilmiş onam metinleri alınmıştır.

Hemogram Kayttları: Çalışma grubunu $(\mathrm{n}=18)$ ve kontrol grubunu $(\mathrm{n}=7)$ oluşturan hastaların hemogram değerlerini oluşturan tam kan analiz verileri oluşturmuştur. Hastanemiz rutin uygulamasinda, hastalardan vena cephalica antebrachii'den alınan $2 \mathrm{ml}$ kan örnekleri EDTA'lı tüplere alınmasının ardından karıştırıcıda orta devirde 5 dakika çevrilerek, BC-5000 Vet Auto Hematoloji cihazıyla çalışılır ve sonuçlar (WBC, NEU, LYM, MONO, EOS, LY\%, MONO\%, EOS\%, NEU\%, RBC, HGB, HCT, MCV, MCH, MCHC, RDW-CV, RDW-SD, PLT, PCT,
MPV, PDW) EVET ${ }^{\circledR}$ hasta kayit programına dijital sistem üzerinden aktarılır. Bu bağlamda yukarıda belirtilen 25 hastanın hemogram kayitlarının hepsine eksiksiz olarak ulaşılmıştır. Çalışma verilerine ait tam kan sayımı değerlerinden NEU/LYM, MONO/LYM ve PLT/LYM değerlerinin elde edilmesinde LYM değerinin ayrı ayrı NEU, MONO ve PLT'e bölünerek hesaplanmasindan yararlanılmıştır (Rossi vd., 2017).

İstatistiksel Analiz: Çalışma ve kontrol gruplarını NEU, LYM, NEU/LYM, PLT, PLT/LYM, MONO, MONO/LYM değerlerinin karşılaştırılmasında "SPSS 21.0.0. Windows" paket programı ile bilgisayar ortamında gerçekleştirilmiştir. Uygun analiz yöntemini belirlemek amacıyla n sayısının 50'den az olmasından ötürü normallik testi için "Shapiro-Wilk" testi ile, diğer analiz yöntemlerinden bağımsız değişkenlerin çarpıklık ve basıklık değerlerine bakılmıștır. Ayrıca, verilerin analizi sırasında, betimleyici istatistiklerin yanı sıra, grupların karşılaştırılmasında "Student $\mathrm{T}$ " testi analizi uygulanmıştır. Analizlerde ise öncelikle varyansların homojen olukları Levene Testi ile de doğrulanmıştır. Analiz sonuçlarında $\mathrm{P}<0,05$ anlamlı olarak kabul edilmiştir.

\section{BULGULAR}

PVE pozitif ve kontrol grubu ortalama NEU, LYM, MONO, PLT, NEU/LYM, MONO/LYM ve PLT/LYM değerleri Tablo 1'de verilmiştir. PVE pozitif köpeklerin ortalama NEU değerlerinin $(1,36)$ kontrol grubu $(8,1)$ ile karşılaştırılmasında PVE grubunun kontrol grubuna göre anlamlı $\mathrm{P}<0,001$ olarak düşük olduğu tespit edilmiştir (Şekil 1). Benzer şekilde gruplar arası ortalama LYM değerinin karşılaştırtılmasında PVE grubu ortalamasının $(0,63)$ kontrol grubuna $(1,62)$ göre anlaml $\mathrm{P}<0,05$ olarak düşük olduğu da tespit edilmiştir (Şekil 1). Bununla birlikte PLT/LYM ortalama değerinin PVE pozitif gruptaki köpeklerde $(1120,94)$ kontrol grubuna $(135,26)$ göre karşılaştırılmasında anlamlı $\mathrm{P}<0,001$ olarak yüksek bulunmuştur (Şekil 1). Diğer taraftan, NEU/LYM, MONO, MONO/LYM ve PLT seviyelerinin grup ortalamalarının karşılaştırmalarında ise istatistiksel farklılıklara rastlanılmamıştır $\mathrm{P}>0,05$ (Şekil 2).

Tablo 1: PVE pozitif ve kontrol gruplarının ortalama NEU, LYM, MONO, PLT, NEU/LYM ve PLT/LYM değerleri.

Table 1: Mean NEU, LYM, MONO, PLT, NEU/LYM and PLT/LYM levels of PVI positive and control groups.

\begin{tabular}{|c|c|c|c|}
\hline \multirow{2}{*}{ Parametre } & \multicolumn{2}{|c|}{ Gruplar } & \multirow{2}{*}{$P$ değeri } \\
\hline & PVE Ortalama & Kontrol Ortalama & \\
\hline NEU $10^{9} / \mathrm{L}$ & $1,38 \pm 1,59$ & $8,10 \pm 2,81$ & 0,000 \\
\hline LYM $10^{9} / \mathrm{L}$ & $0,66 \pm 0,61$ & $1,62 \pm 0,43$ & 0,001 \\
\hline MONO $10^{9} / \mathrm{L}$ & $0,35 \pm 0,34$ & $0,75 \pm 0,44$ & 0,022 \\
\hline PLT $10^{3} / \mathrm{L}$ & $304,33 \pm 116,78$ & $223,57 \pm 110,124$ & 0,121 \\
\hline NEU/LYM & $4,23 \pm 6,19$ & $5,34 \pm 2,74$ & 0,545 \\
\hline MONO/LYM & $1,00 \pm 1,00$ & $0,49 \pm 0,38$ & 0,082 \\
\hline PLT/LYM & $949,08 \pm 763$ & $135,26 \pm 56,66$ & 0,000 \\
\hline
\end{tabular}



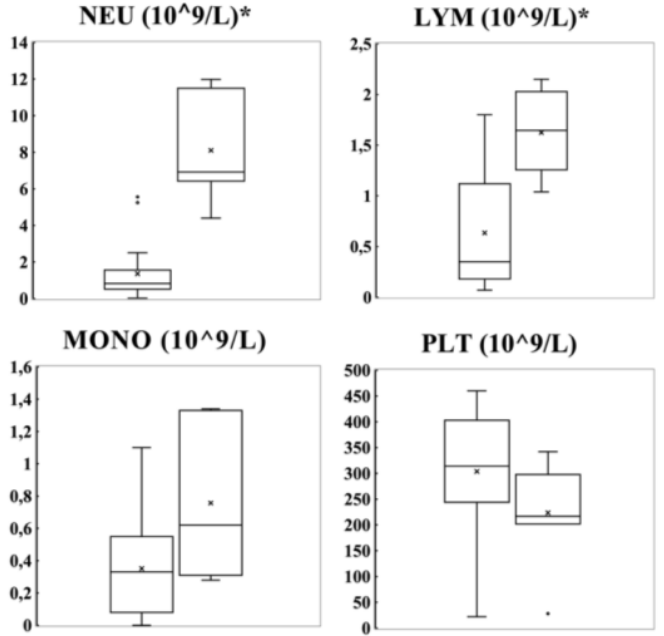

Şekil 1: Solda PVE pozitif ve sağda kontrol köpeklerin NEU, LYM, PLT ve MONO değerlerinin sunulduğu Kutu-Bıyık grafikleri. Orta Kutu, gözlemin \%50'sini oluşturmaktadır; kutunun alt kısmı birinci çeyrekliği ve kutunun üstü üçüncü çeyrekliği oluşturmaktadır. Kutunun ortasındaki yatay çizgi ise medyandır. Her kutudaki çarpı işareti o kutuya ait ortalama değeri vermektedir. Bıyıklar, çeyrekler arası aralıktan 1,5 kez çıkartılan en küçük ve en büyük gözlemlere kadar uzanmaktadır ve ayrı ayrı noktalar halinde belirtilmişlerdir. *İstatiksel olarak anlamlı bulunmuştur.

Figure 1: Box-and-whiskers plot of pretreatment NEU, LYM, MONO, and PLT values in dogs with PVI (left sided boxes) or healthy controls (right sided boxes). The box incorporates the middle $50 \%$ of observation; the bottom of the box is the first quartile (25th percentile) and the top of the box is the third quartile (75th percentile). The horizontal line in the middle of the box is the median (50th percentile). The cross within each box represents the mean value. The whiskers extend to the smallest and largest observations that are 1.5 times removed from the interquartile range are plotted separately as dots. *Found statistically significant.

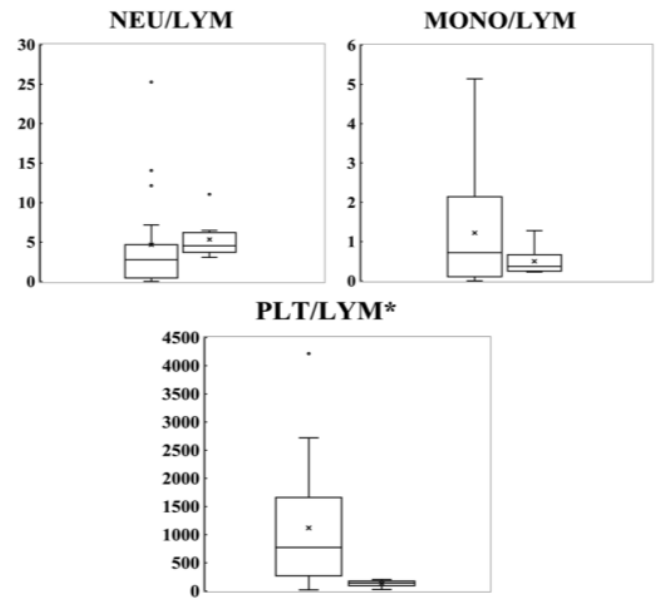

Şekil 2: Solda PVE ile enfekte ve sağda kontrol köpeklerin NEU/LYM, MONO/LYM ve PLT/LYM değerlerinin sunulduğu Kutu-Bıyık grafikleri. Orta Kutu, gözlemin \%50'sini oluşturmaktadır; kutunun alt kısmı birinci çeyrekliği ve kutunun üstü üçüncü çeyrekliği oluşturmaktadır. Kutunun ortasındaki yatay çizgi ise medyandır. Her kutudaki çarpı işareti o kutuya ait ortalama değeri vermektedir. Bıyıklar, çeyrekler arası aralıktan 1,5 kez çıkartılan en küçük ve en büyük gözlemlere kadar uzanmaktadır ve ayrı ayrı noktalar halinde belirtilmişlerdir. *İstatiksel olarak anlamlı bulunmuştur.
Figure 2: Box-and-whiskers plot of pretreatment NEU/LYM, MONO/LYM and PLT/LYM values in dogs with infected PVI (left sided boxes) or healthy controls (right sided boxes). The box incorporates the middle $50 \%$ of observation; the bottom of the box is the first quartile (25th percentile) and the top of the box is the third quartile (75th percentile). The horizontal line in the middle of the box is the median (50th percentile). The cross within each box represents the mean value. The whiskers extend to the smallest and largest observations that are 1.5 times removed from the interquartile range are plotted separately as dots. *Found statistically significant.

\section{TARTIŞMA ve SONUÇ}

1978 'de ortaya çıkmasından bu yana, PVE genç köpeklerde günümüzde halen yaygın ve önemli bir morbidite ve mortalite nedeni olmuştur ve olmaya devam etmektedir. PVE'nun devam eden insidansı, kısmen virüsün kendisini "yenileyebilme yeteneği" ve yeni, daha öldürücü ve dirençli alt varyantlara dönüşme yeteneğinden kaynaklanmaktadır (Goddard \& Leisewitz, 2010). Bu nedenle virüs ile mücadelede öncelik doğru variyanta karşı aşılama olmakla beraber hastalık belirtileri gösteren vakaların erken dönemde teşhis edilmesi hastanın refahı ve tedavi maliyetlerinin artmasının önlenmesi açısından önem arz etmektedir.

Halen PVE'de ucuz ve veteriner hekimlerin başucu olarak tabir edebilen, prognozun ve hastanede yatış süresini belirleyebilen biyo-belirteçler bulunmamaktadır. PVE'de prognostik göstergelerin tanımlanması hastane içi tedavi ve izleminde geliştirilmiştir (Goddard \& Leisewitz, 2010; Schoeman vd., 2013; Mylonakis vd., 2016). Lökopeni (O'Sullivan vd., 1984; Dossin vd., 2011), sistemik inflamatuar yanıt sendromu (Kalli vd., 2010) ve hipokolesterolemi (Yilmaz \& Senturk, 2007) dahil olmak üzere, çoklu potansiyel prognostik göstergelerin azalmış sağkalım ile ilişkili olduğu ortaya konulmuştur ki, bu bulguların öneminin sonraki çalışmalarda her zaman tekrarlanmadığı görülmektedir. Bunların dıșında ek olarak tümör nekrozis faktör aktivitesi (Otto vd., 1997), serum Creaktif protein (McClure vd., 2013), serum kortizol (Schoeman vd., 2007) ve tiroksin (Schoeman \& Herrtage 2007; Schoeman vd., 2008) konsantrasyonları ile son zamanlarda serum Globulin ve Albumin/Globulin oranı gibi (Pekmezci \& Çakır, 2020) ek prognostik göstergeler üzerinde çalışılmıştır. PVE ile ilişkili tarihsel prognostik faktörlerin çoğu, tek değişkenli analizlerle tanımlanmıştır.

Önemli ölçüde geçici bir lenfopeni, PVE'li köpeklerde sıklıkla patognomik bir bulgu olarak kabul edilir ve lökosit sayısında bir azalma ile sonuçlanır (Ling vd., 2012). Hematopoietik progenitör hücrelerin azalması, genellikle hastalı̆̆ın şiddeti ve evresi ile orantılı olan lökopeniye yol açmaktadır (Hoskins, 2001). Nötrofiller ise köpeklerin kanındaki en çok sayıda lökosit türüdür ve istilacı mikroorganizmalara, doku travmasına veya 
herhangi bir kışkırtıcı inflamatuar sinyal yanıtın ilk basamağını oluşturmaktadır.

Sunulan çalışmamızda PVE grubunun sadece ortalama NEU, LYM, değerlerinin kontrol grubuna göre istatistiksel olarak azaldığı görülmüştür. Sunulan çalışmamızda PVE grubu köpeklerde ortalama NEU ve LYM değerleri sırası ile $1,3610^{9} / \mathrm{L}$ ve $0,6310^{9} / \mathrm{L}$ değerleri için daha önce bildirilen çalışmalar ile tutarlı bulunmuştur (Pekmezci \& Çakır, 2020; Ayyıldız \& Tekin, 2021).

İnsanlarda, CBC kullanılarak hesaplanabilen ve kolayca erişilebilen bir parametre olan NEU/LYM, sepsiste morbidite ve mortalitenin bağımsız bir prediktif indeksi olarak kabul görmektedir (Hwang vd., 2017; Naess vd., 2017; Liu vd., 2019; Ni vd., 2019; Huang vd., 2020) ve son zamanlarda köpeklerde yapılan çeşitli bilimsel çalışmalarda bu oranın da çalışılmaya başlanıldığ görülmektedir (Burton vd., 2013; Rejec vd., 2017; Troìa vd., 2017; Hodgson vd., 2018; Çakır \& Pekmezci 2019; Benvenuti vd., 2020; Gori vd., 2021; Neumann, 2021).

Köpeklerde yangısal barsak hastalığında NEU/LYM oranının araştırıldığı bir çalışmada NEU/LYM oranı ile kanin kronik enteropati klinik aktivite indeksi arasında orta dereceli bir korelasyon olduğu ve yangısal barsak hastalığı tanısı almış köpeklerin ortalama NEU/LYM oranlarının 4,28 tespit edilmişken, kontrol grubu olan sağlıklı köpeklerde bu oranın 3 olduğu belirtilmiştir (Benvenuti vd., 2020). Öte yandan Pekmezci ve Çakır (2019) Borrelia burgdorferi ile doğal enfekte köpeklerin NEU/LYM, MONO/LYM ve PLT/LYM oranlarının belirlenmesi ile ilgili gerçekleştirdikleri çalışmalarında $B$. burgdorferi ile enfekte köpeklerin ortalama NEU/LYM, oranlarını 7,2, sağlıklı grup köpeklerin grup ortalamasını ise 5,2 olarak tespit etmişlerdir. Sunulan çalışmamız PVE grubu ortalama PLT/LYM oranlarını 4,65 olarak mevcut çalışmalardan düşük tespit edilirken, kontrol grubumuzu oluşturan sağlıklı köpeklerin ortalama PLT/LYM oranları 5,3 önceki çalışmalar ile paralellik göstermektedir (Çakır \& Pekmezci 2019; Benvenuti vd., 2020).

Septik peritonitli ve sağlıklı köpekler arasında ve hayatta kalanlar ile kalmayanların NEU/LYM'nın karşılaştırıldıkları başka bir çalışmada, gruplar arasında anlamlı bir fark bulunamamıştır (Hodgson vd., 2018). Yine, SIRS ve sepsisli köpeklerde NEU/LYM ve diğer iki lökosit oranı (bant nötrofil-nötrofil-lenfosit oranı (BNLR) ve bant nötrofil-lenfosit oranı (BLR) araştırılan çalışmalarda (Pierini vd., 2019; 2020) NEU/LYM'nın septik köpeklerde SIRS köpeklerine göre daha düşük görüldüğünü, ancak BNLR veya BLR ile sepsis veya mortalite varlığı arasında anlamlı bir ilişki bulunmadığı tespit edilmiştir.

Periodontitisli ve orofarengeal tümörlü köpeklerin NEU/LYM, PLT/LYM ve diğer CBC indekslerinin sağlıklı köpekler ile karşılaştırıldığı retrospektif bir çalışmada araştırmacılar sağlıklı köpeklerin $(n=71)$ ortalama PLT/LYM değerlenin diğer gruplara göre en düşük $(145,31)$, periodontitisli ve orofarengeal grupların PLT/LYM değerlerinin ise sırası ile 224 ve 290,5 olduğunu tespit etmişlerdir (Rejec vd., 2017). Sunulan çalışmamızda ise kontrol grubu ortalama PLT/LYM değerimiz $(135,26)$ Rejec vd. 2017 (145,31) ve Çakır \& Pekmezci (2019) (182,8) ile benzer bulunmuş olup, PVE grubu ortalama PLT/LYM değerimizin ise 1120,94 oldukça yüksek olduğu tespit edilmiştir. Çakır ve Pekmezci (2019) B. burgdorferi ile enfekte köpeklerin ortalama PLT/LYM oranlarını 242,2 olarak tespit etmişlerdir. Son yapılan bir çalışmada ise Neumann (2021) akut pankreatitisli kedi ve köpeklerdeki NEU/LYM ve PLT/LYM oranlarının sağlıklı kontroller ile karşılaştırdığı çalışmasında sağlıklı köpeklerin PLT/LYM ortalamalarının 164, akut pankreatitisli köpeklerin ise 257 olduğunu tespit etmişlerdir. Mevcut çalışmamız kontrol grubu köpeklerimizdeki ortalama PLT/LYM değerimizin $(135,26)$ diğer çalışmalar ile benzerlik gösterirken, PVE grubumuz ortalama PLT/LYM değerimizin (1120,94) diğer köpek çalışmalarına kıyasla oldukça yüksek olduğu görülmektedir (Rejec vd., 2017; Çakır \& Pekmezci, 2019; Neumann, 2021).

Trombositlerin inflamasyon ve enfeksiyondaki rolü bilinmektedir; trombositler fagositozis ile lökositozis fonksiyonunu modüle etmektedirler (Jenne \& Kubes, 2015). Bu nedenle, mevcut çalışma sonucunda PVE'deki vakalarda yüksek PLT/LYM ortalamalarının sebebi de bu şekilde açıklanabilir. Ancak, tek başına trombosit sayısının değerlendirilmesi elbette ki akut ve kronik enfeksiyonlarda yeterli olmayacaktır.

Köpeklerin çeşitli hastalıklarda MONO/LYM oranlarının araştırıldığı çalışma sayısı oldukça kısıtlı olmakla beraber Çakır ve Pekmezci (2019) B. burgdorferi ile enfekte köpeklerin MONO/LYM sağlıklı grup ile karşılaştırdığı ve istatistiksel olarak bir fark bulamadıkları çalışmalarında, ortalama MONO/LYM oranlarını ise sırası 0,7 ve 0,4 tespit etmişlerdir. Mevcut çalışmada benzer bir durum görülmekle beraber PVE grubu ortalama MONO/LYM oranı 1,2 kontrol grubu ise 0,4 olarak bulunmuştur.

Sonuç olarak, sunulan bu ön çalışma PLT/LYM oranının, tedavi öncesi PVE enfekte olmuş köpeklerde yüksek seviyelerde görülmesinin tanının doğrulanması yönünde, kolay, düşük maliyetli, objektif ve invazif olmayan prognostik biyobelirteç adayı olabileceğini düşündürmektedir. Bununla birlikte veteriner hekimlikte NEU/LYM, MONO/LYM, PLT/LYM oranları ile ilgili daha ileri çalışmaların yapılması gerektiği kanaatine varılmaktadır. 


\section{KAYNAKLAR}

Apaa, T.T., Daly, J.M. \& Tarlinton, R.E. (2016). Canine parvovirus (CPV-2) variants circulating in nigerian dogs. Veterinary Record Open, 3.

Ayyıldız, M. \& Tekin, M.E. (2021). Köpeklerin parvoviral enterit hastalığ değerlerinin ROC eğrisi ile incelenmesi. Eurasian Journal of Veterinary Sciences, 37(2), 101-108.

Benvenuti, E., Pierini, A., Gori, E., Lucarelli, C., Lubas, G. \& Marchetti, V. (2020). Neutrophil-tolymphocyte ratio (nlr) in canine inflammatory bowel disease (IBD). Veterinary Sciences, 7(3), 141.

Burton, A.G., Harris, L.A., Owens, S.D. \& Jandrey, K.E. (2013). The prognostic utility of degenerative left shifts in dogs. Journal of Veterinary Internal Medicine, 27, 1517-1522.

Cavalli, A., Desario, C., Kusi, I., Mari, V., Lorusso, E., Cirone, F. Kumbe, I., Colaianni, M.L., Buonavoglia, D. \& Decaro, N. (2014). Detection and genetic characterization of canine parvovirus and canine coronavirus strains circulating in district of Tirana in Albania. Journal of Veterinary Diagnostic Investigation, 26, 563-566.

Chandrashekara, S., Mukhtar Ahmad, M., Renuka, P., Anupama, K.R. \& Renuka, K. (2017). Characterization of neutrophil-to-lymphocyte ratio as a measure of inflammation in rheumatoid arthritis. International Journal of Rheumatic Diseases, 20(10), 1457-1467.

Çakır, K. \& Pekmezci, D. (2019). Borrelia burgdorferi ile doğal enfekte köpeklerin nötrofil-lenfosit, monositlenfosit ve platelet-lenfosit oranlarının belirlenmesi. Etlik Veteriner Mikrobiyoloji Dergisi, 30(1), 58-63.

Decaro, N. \& Buonavoglia, C. (2012). Canine parvovirus-a review of epidemiological and diagnostic aspects, with emphasis on type 2c. Veterinary Microbiology, 155, 1-12.

Decaro, N., Cirone, F., Desario, C., Elia, G., Lorusso, E., Colaianni, M.L., Martella, V. \& Buonavoglia, C. (2009). Severe parvovirus in a 12-year-old dog that had been repeatedly vaccinated. Veterinary Record, 164, 593-595.

Decaro, N., Desario, C., Billi, M., Mari, V., Elia, G., Cavalli, A., Martella, V., \& Buonavoglia, C. (2011). Western European epidemiological survey for parvovirus and coronavirus infections in dogs. The Veterinary Journal, 187, 195-199.

Dik, I. \& Şimşek, A. (2021). Comparison of different diagnostic methods in detection of canine parvovirus infection. Eurasian Journal of Veterinary Sciences, 37(2), 76-81.

Dossin, O., Rupassara, S.I., Weng, H.Y., Williams, D.A., Garlick, P.J. \& Schoeman, J.P. (2011). Effect of parvoviral enteritis on plasma citrulline concentration in dogs. Journal of Veterinary Internal Medicine, 25(2), 215-221.

Duijvestijn, M., Mughini-Gras, L., Schuurman, N., Schijf, W., Wagenaar, J.A. \& Egberink, H. (2016). Enteropathogen infections in canine puppies: (co-) occurrence, clinical relevance and risk factors. Veterinary Microbiology, 195, 115-122.

Duque-García, Y., Echeverri-Zuluaga, M., Trejos-Suarez, J. \& Ruiz-Saenz, J. (2017). Prevalence and molecular epidemiology of canine parvovirus 2 in diarrheic dogs in Colombia, South America: a possible new cpv-2a is emerging? Veterinary Microbiology, 201, 56-61.

Filipov, C., Desario, C., Patouchas, O., Eftimov, P., Gruichev, G., Manov, V., Filipov, G., Buonavoglia, C. \& Decaro, N. (2016). A ten-year molecular survey on parvoviruses infecting carnivores in Bulgaria. Transboundary and Emerging Diseases, 63, 460-464.

Gargari, S. (2015). Gastroenteritis semptomlu köpeklerde canine parvovirus tip-2'nin tespiti ve moleküler karakterizasyonu. Doktora Tezi, Ankara Üniversitesi Sağlık Bilimleri Enstitüsü. Ankara, Türkiye, 108s.

Goddard, A. \& Leisewitz, A.L. (2010). Canine parvovirus. Veterinary Clinics of North America: Small Animal Practice, 40, 1041-1053.

Gori, E., Pierini, A., Lippi, I., Lubas, G. \& Marchetti, V. (2021). Leukocytes ratios in feline systemic inflammatory response syndrome and sepsis: a retrospective analysis of 209 cases. Animals, 6, 1644.

Hodgson, N., Llewellyn, E.A. \& Schaeffer, D.J. (2018). Utility and Prognostic Significance of Neutrophil-toLymphocyte Ratio in Dogs with Septic Peritonitis. Journal of the American Animal Hospital Association, 54, 351-359.

Hoskins, J.D. (2001). Canine viral enteritis, In: Ettinger, S.J. (Ed), Pocket Companion to Text Book of Veterinary Internal Medicine. 5th ed., 214-218p, WB Saunders Company, Philadelphia, USA.

Hoskins, JD. (1997). Update on canine parvoviral enteritis. Veterinary Medicine, 92(8), 694-709.

Huang, Z., Fu, Z., Huang, W. \& Huang, K. (2020). Prognostic value of neutrophil-to-lymphocyte ratio in sepsis: A meta-analysis. American Journal of Emergency Medicine, 38, 641-647.

Hwang, S.Y., Shin, T.G., Jo, I.J., Jeon, K., Suh, G.Y., Lee, T.R., Yoon, H., Cha, W.C. \& Sim, M.S. (2017). Neutrophil-to-lymphocyte ratio as a prognostic marker in critically-ill septic patients. American Journal of Emergency Medicine, 35, 234-239.

Jenne, C.N. \& Kubes, P. (2015). Platelets in inflammation and infection. Platelets, 26(4), 286-292.

Kalli, I., Leontides, L.S., Mylonakis, M.E., AdamamaMoraitou, K., Rallis, T. \& Koutinas, A.F. (2010). Factors affecting the occurrence, duration of hospitalization and final outcome in canine parvovirus infection. Research in Veterinary Science, 89(2), 174-178.

Li, H., Zhou, Y., Ma, Y., Han, S. \& Zhou, L. (2017). The prognostic value of the platelet-to- lymphocyte ratio in acute coronary syndrome: a systematic review and meta-analysis. Kardiologia Polska, 75(7), 666-673.

Ling, M., Norris, J.M., Kelman, M. \& Ward, M.P. (2012). Risk factors for death from canine parvoviral related disease in Australia. Veterinary Microbiology, 158, 280-290.

Liu, Y., Zheng, J., Zhang, D. \& Jing, L. (2019). Neutrophillymphocyte ratio and plasma lactate predict 28-day mortality in patients with sepsis. Journal of Clinical Laboratory Analysis, 33, e22942.

McClure, V., van Schoor, M., Thompson, P.N., KjelgaardHansen, M. \& Goddard, A. (2013). Evaluation of the use of serum C-reactive protein concentration to 
predict outcome in puppies infected with canine parvovirus. Journal of the American Veterinary Medical Association, 243(3), 361-366.

Mohr, A.J., Leisewitz, A.L., Jacobson, L.S., Steiner, J.M., Ruaux, C.G. \& Williams, D.A. (2003). Effect of early enteral nutrition on intestinal permeability, intestinal protein loss, and outcome in dogs with severe parvoviral enteritis. Journal of Veterinary Internal Medicine, 17, 791-798.

Mylonakis, M.E., Kalli, I. \& Rallis, T.S. (2016). Canine parvoviral enteritis: an update on the clinical diagnosis, treatment, and prevention. Veterinary Medicine, 7, 91-100.

Naess, A., Nilssen, S.S., Mo, R., Eide, G.E. \& Sjursen, H. (2017). Role of neutrophil to lymphocyte and monocyte to lymphocyte ratios in the diagnosis of bacterial infection in patients with fever. Infection, 45, 299-307.

Neumann, S. (2021). Neutrophil-to-lymphocyte and plateletto-lymphocyte ratios in dogs and cats with acute pancreatitis. Veterinary Clinical Pathology, 50(1), $45-45$.

Ni, J., Wang, H., Li, Y., Shu, Y. \& Liu, Y. (2019). Neutrophil to lymphocyte ratio (NLR) as a prognostic marker for in-hospital mortality of patients with sepsis: A secondary analysis based on a single-center, retrospective, cohort study. Medicine, 98, e18029.

O'Sullivan, G., Durham, P.J., Smith, J.R. \& Campbell, R.S. (1984). Experimentally induced severe canine parvoviral enteritis. Australian Veterinary Journal, 61(1),1-4.

Otto, C.M., Drobatz, K.J. \& Soter, C. (1997). Endotoxemia and tumor necrosis factor activity in dogs with naturally occurring parvoviral enteritis. Journal of Veterinary Internal Medicine, 11(2), 65-70.

Pekmezci, D. \& Çakır, K. (2020). Doğal parvovirus ile enfekte köpeklerde tedavi öncesi serum albuminin globuline oranının değerlendirilmesi. Anadolu Çevre ve Hayvancilık Dergisi, 5(2), 118-124.

Pierini, A., Gori, E., Lippi, I., Ceccherini, G., Lubas, G. \& Marchetti, V. (2019). Neutrophil-to-lymphocyte ratio, nucleated red blood cells and erythrocyte abnormalities in canine systemic inflammatory response syndrome. Research in Veterinary Science, 126, 150-154.

Pierini, A., Gori, E., Lippi, I., Lubas, G. \& Marchetti, V. (2020). Are leukocyte and platelet abnormalities and complete blood count ratios potential prognostic markers in canine sepsis? Frontiers in Veterinary Science, 7, 578846.

Prittie, J. (2004). Canine parvoviral enteritis: a review of diagnosis, management, and prevention. Journal of Veterinary Internal Medicine, 14, 167-176.

Rejec, A., Butinar, J., Gawor, J. \& Petelin, M. (2017). Evaluation of complete blood count indices (NLR, PLR, MPV/PLT, and PLCRi) in healthy dogs, dogs with periodontitis and dogs with oropharyngeal tumors as potential biomarkers of systemic inflammatory response. Journal of Veterinary Dentistry, 34, 231-240.

Rossi, S., Basso, M., Strippoli, A., Schinzari, G., D'Argento, E., Larocca, M., Cassano, A. \& Barone, C. (2017). Are markers of systemic inflammation good prognostic indicators in colorectal cancer? Clin Colorectal Cancer, 16, 264274.

Schoeman, J.P. \& Herrtage, M.E. (2008). Serum thyrotropin, thyroxine and free thyroxine concentrations as predictors of mortality in critically ill puppies with parvovirus infection: a model for human paediatric critical illness? Microbes and Infection, 10(2), 203-207.

Schoeman, J.P., Goddard, A. \& Herrtage, M.E. (2007). Serum cortisol and thyroxine concentrations as predictors of death in critically ill puppies with parvoviral diarrhea. Journal of the American Veterinary Medical Association, 231(10), 15341539.

Schoeman, J.P., Goddard, A. \& Leisewitz, A.L. (2013). Biomarkers in canine parvovirus enteritis. New Zealand Veterinary Journal, 61, 217-222.

Shi, L., Qin, X., Wang, H., Xia, Y., Li, Y., Chen, X., Shang, L., Tai, Y.T., Feng, X., Acharya, P., Acharya, C., Xu, Y., Deng, S., Hao, M., Zou, D., Zhao, Y., Ru, K., Qiu, L. \& An, G. (2017). Elevated neutrophilto-lymphocyte ratio and monocyte-to-lymphocyte ratio and decreased platelet-to-lymphocyte ratio are associated with poor prognosis in multiple myeloma. Oncotarget, 8(12), 18792-18801.

Smith-Carr, S., Macintire, D.K. \& Swango, L.J. (1997). Canine parvovirus. Part I. Pathogenesis and vaccination. Compendium on Continuing Education for the Practising Veterinarian, 19(2), 125-133.

Summers, C., Rankin, S.M., Condliffe, A.M., Singh, N., Peters, A.M. \& Chilvers, E.R. (2010). Neutrophil kinetics in health and disease. Trends in Immunology, 31(8), 318-324.

Troìa, R., Agnoli, C., Calipa, S., Segalina, S., Murgia, E., Gruarin, M., Dondi, F. \& Giunti, M. (2017). Evaluation of the delta neutrophil index from an automated blood cell analyser in septic dogs. The Veterinary Journal, 230, 13-19.

Wang, Y., Fuentes, H.E., Attar, B.M., Jaiswal, P. \& Demetria, M. (2017). Evaluation of the prognostic value of neutrophil to lymphocyte ratio in patients with hypertriglycer- idemia-induced acute pancreatitis. Pancreatology, 17(6), 893-897.

Yao, C., Liu, X. \& Tang, Z. (2017). Prognostic role of neutrophil-lymphocyte ratio and pla- teletlymphocyte ratio for hospital mortality in patients with AECOPD. International Journal of Chronic Obstructive Pulmonary Disease, 12, 2285-2290.

Yilmaz, Z. \& Senturk, S. (2007). Characterization of lipid profiles in dogs with parvoviral enteritis. Journal of Small Animal Practice, 48, 643-650.

Zhao, Z., Liu, H., Ding, K., Peng, C., Xue, Q., Yu, Z. \& Xue, Y. (2016). Occurrence of canine parvovirus in dogs from Henan province of China in 2009-2014. $B M C$ Veterinary Research, 12. 